\title{
Correction to: In vitro exposed magnesium oxide nanoparticles enhanced the growth of legume Macrotyloma uniflorum
}

\author{
Priya Sharma ${ }^{1} \cdot$ Ayushi Gautam ${ }^{1} \cdot$ Vineet Kumar $^{2} \cdot$ Praveen Guleria $^{1}$ (D)
}

Published online: 24 November 2021

๑) Springer-Verlag GmbH Germany, part of Springer Nature 2021

\section{Correction to: Environmental Science and Pollution Research https://doi.org/10.1007/s11356-021-16828-5}

The correct affiliation of Praveen Guleria is modified in the published proof.

The Original article has been corrected.

Publisher's note Springer Nature remains neutral with regard to jurisdictional claims in published maps and institutional affiliations.

The original article can be found online at https://doi.org/10.1007/ s11356-021-16828-5

Vineet Kumar

vineetkumar22@gmail.com

$\bowtie$ Praveen Guleria

pvihbt@gmail.com

Priya Sharma

psdavuniversity@gmail.com

Ayushi Gautam

agdavuniversity@gmail.com

1 Plant Biotechnology and Genetic Engineering Lab,

Department of Biotechnology, DAV University, Jalandhar,

Punjab 144012, India

2 Department of Biotechnology, School of Bioengineering and Biosciences, Lovely Professional University, Phagwara, Punjab 144111, India 